\title{
Life Cycle Sustainability Analysis of Resource Recovery from Waste Management Systems in a Circular Economy Perspective Key Findings from This Special Issue
}

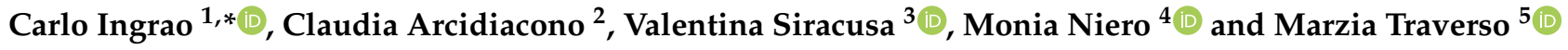 \\ 1 Department of Economics, University of Foggia, 71121 Foggia, Italy \\ 2 Department of Agriculture, Food and Environment (Di3A), University of Catania, 95123 Catania, Italy; \\ claudia.arcidiacono@unict.it \\ 3 Department of Chemical Sciences, University of Catania, 95125 Catania, Italy; vsiracus@dmfci.unict.it \\ 4 Department of Planning, Aalborg University, 2450 Copenhagen, Denmark; monian@plan.aau.dk \\ 5 Institute of Sustainability in Civil Engineering (INaB), RWTH Aachen University, 52074 Aachen, Germany; \\ marzia.traverso@inab.rwth-aachen.de \\ * Correspondence: carlo.ingrao@unifg.it
}

Citation: Ingrao, C.; Arcidiacono, C.; Siracusa, V.; Niero, M.; Traverso, M. Life Cycle Sustainability Analysis of Resource Recovery from Waste Management Systems in a Circular Economy Perspective Key Findings from This Special Issue. Resources 2021, 10, 32. https://doi.org/10.3390/ resources 10040032

Received: 22 March 2021

Accepted: 8 April 2021

Published: 9 April 2021

Publisher's Note: MDPI stays neutral with regard to jurisdictional claims in published maps and institutional affiliations.

Copyright: () 2021 by the authors. Licensee MDPI, Basel, Switzerland. This article is an open access article distributed under the terms and conditions of the Creative Commons Attribution (CC BY) license (https:// creativecommons.org/licenses/by/ $4.0 /)$.

\section{Introduction}

The generation and management of waste are gaining increasing attention worldwide as two main focuses of the environmental strategies and policies developed to date at the European level [1]. Several regulations, such as the Waste Framework Directive [2], have been applied over the years with the aim of pursuing environmental objectives, preventing possible risks to human health and introducing numerous innovations in the classification of waste, as well as in the options for their recovery or disposal. In this regard, affordable, effective and truly sustainable waste management systems can make the difference and significantly contribute to sustainable development [3]. It can help to mitigate the exploitation of material and energy resources due to increasing globalisation and industrialisation [4]. To this end, there is an urgent need that waste management policies are elaborated to set and promote integrated strategies for optimisation of waste recycling pathways starting from separate-municipal collection. Landfill is highly impacting in terms of resource depletion and environmental pollution, whilst recycling not only increases the efficiency of resources but, also, reduces the environmental impacts associated with products' life cycles [5]. Hence, measures and actions should be taken to implement sustainable integrated waste management systems that minimise the environmental impact associated with waste management, and favour waste recovery and recycling [6,7].

Within this context, valorisation of waste through its conversion into value-added materials is a key principle of the Circular Economy (CE) which is increasingly attracting researchers, producers and decision- and policy-makers. The CE concept has become well known and researched in recent years, mainly through the EU's Action Plans that have been released over the years up to the 2020 version [8], but its scientific foundations have been known for quite a long time [9]. CE has been introduced as a valid alternative to a linear economy concept, which has dominated for the last 150 years, as it promotes long-term sustainability by maintaining products, components and materials at their highest level of utility and value, whilst minimising resource exploitation and waste generation $[10,11]$. $\mathrm{CE}$ is seen, in fact, as a sustainable economic model where economic growth is decoupled from material consumption through natural resource reduction and recirculation [12]. This is based upon the principle that goods at the end of their life cycles, as well as the waste generated during the manufacturing and use/maintenance of those goods, are reutilised as zero-burden resources that go to feed recycling processes for production of secondary raw materials $[10,12]$. 
CE can be seen as a condition for sustainability, as it acts like a regenerative system that minimises material and energy inputs, as well as emissions and waste, by slowing and closing the resource loops $[13,14]$. It is, however, desirable that CE-oriented measures are tested with the support of tools like Life Cycle Sustainability Assessment (LCSA) and LCA already in the design phase, so that CE can be truly effective in making material and energy commodities holistically sustainable in a life cycle perspective.

$\mathrm{CE}$ can be considered as an economic system which, through reduction, reuse, recycle and recovery of materials in production and consumption systems, aims at accomplishing sustainable development and, at the same time, environmental quality, economic prosperity and social equity $[15,16]$.

Under this perspective, CE is relevant for a huge number of sectors, and can contribute to sustainable development pathways at the urban and rural context [17].

Waste streams are increasingly being used for production of material commodities usable in a wide range of sectors-research is, therefore, needed to make innovations and improvements that are based upon application of CE principles. For this purpose, studies were developed-and many others are expected in the future-to address the three dimensions of sustainability in the waste management field, and to support the development of strategies, guidelines and policies that are oriented towards the creation of holistically-sustainable CE models. There are, however, developments in the CE field that may be not so advantageous for the environment as expected or are, at least, less advantageous than others [18].

This results in the need and importance of selecting the CE scenarios that should be prioritised and integrated into policies and measures oriented to climate change prevention and environmental protection. For this purpose, scientists, producers, policy- and decision-makers and other stakeholders need to be able to compare those actions to identify the most environmentally and socio-economically sustainable [19]. In this regard, the specialised literature documented LCSA to be a holistic methodology for the assessment of the environmental, economic and social dimension of sustainability of CE scenarios in a life cycle perspective $[20,21]$. LCSA is the complementary implementation of LCA, Life Cycle Costing (LCC) and Social Life Cycle Assessment (SLCA) [20]. The LCSA concept was introduced for the first time in 2007 by Finkbeiner [22], and later was recalled and expanded by Klöpffer [23]. Its implementation in the waste sector is, however, not so widespread, though it would be hugely beneficial for its sustainability enhancement. By contrast, LCA has been extensively and successfully applied to assess the potential environmental impacts of different waste management systems [24,25]. Thus, both LCA and LCSA show great potential in being applied to test the extent to which circular models of the economy are beneficial compared with the linear ones or to identify which is the best circular economy strategy, among different alternatives, e.g., recycling or reuse. This is achieved by addressing trade-offs both between life cycle stages and between different sustainability dimensions [21]. However, there are challenges connected with the application of LCA to waste management studies which are relevant in a CE context, such as the modelling of recycling processes and substitutability of secondary materials [26,27].

Challenges increase, however, when it comes to application of the newest of those LCA-based methodologies (i.e., SLCA), for the assessment of the social dimension of sustainability of waste management systems. This is mainly because of the lack of quite sensitive data needed for the social modelling. Such a limitation can be observed also in this Special Issue, where most of the studies focus on the assessment of the environmental dimension.

Under this perspective, the Special Issue (SI) was published in this journal to motivate prominent researchers to explore the relevance of assessing-and possibly integratingthose dimensions for the improvement and promotion of sustainable CE-based waste management systems. 


\section{Scope of This Special Issue}

This SI was developed based upon the concern that sustainable waste management under the CE perspective can contribute to the transition towards equitable, sustainable, post fossil-carbon societies, as also highlighted by Ingrao et al. [28]. It is time for CE-based societies where responsible and sustainable manners of managing waste are implemented and pursued. A successful transition should be, however, envisioned, designed, tested and implemented to ensure production, distribution and consumption of value-added waste-derived commodities that respond to the three dimensions of sustainability, or to the seventeen United Nations sustainable development goals [28,29].

In this context, this SI attempts to highlight the importance of academic research to assess and stimulate holistically integrated sustainability of waste recovery systems in a CE perspective. By doing so, the SI could serve as a platform for enhancement of knowledge on emerging methods, practical implementations, state-of-the-art analyses, findings and lessons learned in this research content area.

Finally, as the conclusive step of the SI development, this editorial was developed to review and build upon the seven collected papers, to highlight their main objectives and findings and, so, their contributions to $\mathrm{CE}$ research.

\section{Overview of the Papers Included in This Special Issue}

The SI attracted considerable interest and attention from the scientific community worldwide with a total of seven papers published between 2019 and 2020. The papers were submitted by seven authors from several countries worldwide, and were the result of the joint work and commitment made by a total of 30 authors coming from Germany, Italy, Malaysia and Colombia, and often belonging to institutions doing research in different but complementary subjects. This highlights how research in this field is quite diversified and complex and requires a multidisciplinary perspective.

In all contributions, the authors explored several relevant aspects connected with this SI's research theme, so enriching the current state-of-the-art in the field of sustainable waste recovery systems for production of value-added commodities under a CE perspective.

Some of the sectors where CE can be beneficial for enhancement of their sustainability performance were explored in this SI's paper collection: post-use plastics end-of-life [11,30]; waste heat recovery [31]; waste management [32,33]; electrics and electronics [34]; and olive oil [35].

Several methodologies and indicators were used for investigation of those sectors, namely:

- $\quad$ Midpoint Life Cycle Assessment (LCA) focussed upon a single Environmental Indicator (EI), as done by Spierling et al. [30];

- $\quad$ Midpoint LCA of multiple EIs [11];

- $\quad$ Endpoint LCA of multiple EIs extended to other relevant issues [31];

- $\quad$ Life-cycle multicriteria analysis as a decision support tool [32];

- $\quad$ Strengths, Weaknesses, Opportunities and Threats (SWOT) analysis combined with other environmental assessment methodologies [33];

- Questionnaire-based investigation [34];

- Questionnaire-based investigation combined with a SWOT analysis [35].

Therefore, it can be highlighted that there exists a remarkable heterogeneity in terms of the methodologies and indicators that can be used for assessment and improvement of holistically sustainable CE models.

The seven papers are reviewed in the following sections using a methodology-based classification.

\subsection{Midpoint LCA Considering a Single Environmental Indicator}

In their study, Spierling et al. [30] carried out a comprehensive review of the current status of end-of-life options for bio-based plastics using the Global Warming Potential (GWP) as an environmental indicator. The review highlighted that a lot of attention is cur- 
rently given to Poly-lactic Acid (PLA), and all feasible end-of-life options are investigated in the literature. Through the review, it was proven that mechanical recycling of post-use PLA artefacts generates the highest GWP savings over the virgin counterpart amongst all types of bio-plastics reviewed by the authors.

Plastics are a group of versatile polymeric materials [30] that are increasingly dominating the market, as they lend themselves to application in a wide range of sectors-the leader amongst them is packaging. In this sector, recently there has been an upsurge in the interest for returnable packages from various industrial end-users like food and beverages, consumer goods and several others [11]. The reuse of a product for the same initial purpose can significantly contribute to meeting the $\mathrm{CE}$ feature of slowing the resource loop, thus contributing to making products' life cycles more sustainable [11]. The products' reusability principle can be highly beneficial for the packaging sector from both an economic and environmental perspective, in regard to categories of reusable packages like pallets, crates, bottles and several others [11]. This research content area was investigated by Tua et al. [11], who carried out a multiple-issue environmental assessment; the paper is reviewed in the next dedicated section.

\subsection{Midpoint LCA Considering Multiple Environmental Indicators}

In their article, Tua et al. [11] reported upon an LCA application experience to identify the environmental hotspots associated with the life cycle of Reusable Plastic Crates (RPCs) for the distribution of fruits and vegetables in Italy, considering the number of provided deliveries, from 1 to 125 . To that end, the authors carried out a full LCA that considered a set of system representative midpoint EIs, complemented with the cumulative energy demand and a tailor-made water consumption indicator. Attaining the proposed goal, the authors documented that when RPCs are used for less than 20 deliveries, manufacturing is the phase dominating the impacts associated with the crates' life cycle. If the number of deliveries performed increases, the contribution of RPC reconditioning increases, subsequently covering $30-70 \%$ of the life cycle impacts for 125 deliveries. This should be attributed to the increase in the transportation of the crates from the users to the plant, and in the consumption of electricity, heat and washing water. Moreover, Tua et al. [11] nicely proved that a minimum of three deliveries is required for the re-use system to perform better than an alternative distribution system of fruits and vegetables, where single-use plastic crates are sent to recycling and replaced with new ones.

\subsection{Endpoint LCA of Multiple Environmental Indicators, Extended to Other Relevant Issues}

Energy consumption is a key aspect in any industrial system, which is confirmed by the fact that the industrial sector represents $35-40 \%$ of the global final energy use [36]. The consumption of non-renewable energy is responsible for a set of environmental impacts that mainly include the exploitation of fossil resources like coal, oil and natural gas, and the emissions of greenhouse gases (GHGs) [31]. This puts emphasis upon the urgent need to transition towards cleaner energy substitutes to protect the environment and support sustainable development [31]. A key role in this sense could be played by systems based upon the Organic Ranking Cycle (ORC) for waste heat recovery-this research content area has been widely investigated in the literature [31]. In this context, Ochoa et al. [31] integrated an ORC system into a $2 \mathrm{MW}$ natural gas engine for electricity generation through recovery of the engine's exhaust heat. For this purpose, the authors carried out a full endpoint LCA integrated with the assessment of exergetic and economic issues as connected with the system investigated.

Through their study, the authors determined the design and operational variables that most contributed to the relevant exergy, economic and environmental issues associated with such an energy system, namely the evaporation pressure, the heat transfer area and the turbine technology efficiency. 


\subsection{Life-Cycle Multicriteria Analysis as a Decision Support Tool}

Waste management is a complex process, especially under emergency conditions, and requires proper handling - the sudden closure of a landfill, and the subsequent identification of new waste disposal sites, can be one of those conditions. It can generate severe environmental and health problems that need to be addressed and solved [32].

Under this perspective, Moreschi et al. [32] analysed the closure of a municipal solid waste landfill in the territory of Genoa (Italy) to implement a Decision Support System (DSS) that would improve waste management, especially when emergencies occurred. The DSS was proven as useful and effective to perform different optimisations and system analyses for improved waste management, starting from long-term planning to day-by-day scheduling in case of emergency, relying only upon third parties' waste disposal plants. In this context, the tool was documented as enabling to achieve longstanding targets in terms of total costs, emissions generated by waste transport and exploitation of a single plant from a sustainability point of view [32].

The waste management investigation was narrowed to the maritime sector in the study of Gallo et al. [33], which is reviewed in the next section, as it reports upon findings from the combined application of SWOT analysis and the methodology developed by the United Nations Framework Convention on Climate Change (UNFCCC).

\subsection{SWOT Analysis Combined with Other Environmental Assessment Methodologies}

Gallo et al. [33] investigated the type and amount of waste that is generated on average by a typical cruise ship, with a 5000 people hosting capacity, a $300 \mathrm{~m}$ length, and a $100 \mathrm{kt}$ tonnage. The authors' attention fell on this research field because such a ship is like a small floating city that, depending upon logistical and management peculiarities, can generate even huge amounts of highly diversified waste [33]. In their study, the authors analysed a set of on-board waste management solutions in a CE perspective, based upon their GHG reduction potential regardless of routes and ports of destinations. To that end, Gallo et al. [33] applied the SWOT analysis to a set of waste management options for the estimation of the related issues of GHG emissions, cost, environmental sustainability, methodological coherence, feasibility and replicability, and determined the following ones to be of particular interest-the thermos-chemical treatment of properly collected waste oils and sludge for conversion into fuel oils, and the installation on board of a waste-toenergy plant with energy recovery. Then, for those two options, the authors carried out a complementary assessment of the GHG-emission reduction following their application, using the UNFCCC methodologies—-the study highlighted no particularly significant reduction in that sense. According to Gallo et al. [33], this should be attributed to the lack of GHG assessment methodologies that are calibrated not just for stationary waste treatment plants-as are the UNFCCC methodologies—but also to take into account the peculiarities and hotspots of plant design and management methods on board the ship.

\subsection{Questionnaire-Based Investigation}

Through their study, Gallo et al. [33] contributed to the understanding that strategies are needed for creation of a sustainable $\mathrm{CE}$, starting with taking initiatives in the manufacturing phase to reduce material usage and waste generation. Under this perspective, Ho et al. [34] focalised attention upon the material efficiency strategy that-as they state-has received limited attention with respect to strategies aimed at managing products' endof-life. Material efficiency plays a central role for $\mathrm{CE}$ promotion by minimising resource utilisation and by returning outdated products to the material chain through programs like the "take-back". Material efficiency strategies are, however, perceived differently by different types of manufacturing companies [34,37]. Therefore, agreeing with Ho et al. [34], this SI's editors believe that the understanding of the material efficiency strategies adopted by a specific company could help to find effective solutions for sustainable material usage. As a matter of fact, Ho et al. [34] investigated the case of Malaysian companies working in the field of Electrics and Electronics (E\&E), and carried out a qualitative investiga- 
tion based upon semi-structured interviews to highlight the material efficiency strategies adopted in such a manufacturing industry. Eleven strategies were determined by the authors, with most of them being oriented to ameliorate the product design phase starting from the material preparation and acquisition, with the final aim of meeting sustainable development.

\subsection{Questionnaire-Based Investigation Combined with a SWOT Analysis}

In the area of making strategies, $\mathrm{D}^{\prime}$ Adamo et al. [35] carried out a socioeconomic assessment for identification of opportunities that enable CE development in the olive sector. In particular, they applied a SWOT analysis integrated with a questionnaire-based methodology, with the aim of gathering the perspectives of 500 consumers on the role of family business and on whether the olive oil residue management can provide prospects according to the $\mathrm{CE}$ principles. Three categories of consumers were involved for the survey development-consumers of family-owned Olive Oil Mills (OOMs), which are, and alternatively are not, also olive producers, and final olive oil consumers. The final aim of this interesting combined assessment was to learn about the extent to which the involved consumers' insights can be informative of the strengths, weaknesses, opportunities and threats of the investigated sector. Attention was on the olive oil sector because it is characterised by the presence of family business, and so the authors thought it was worth studying the existence of a "family business brand" effect on consumers' perceptions [35]. In addition to this, the olive oil sector is characterised by a high level of competition, in which large firms are involved in the crushing of olives coming from several regions, thus optimising the processing time and the olive production costs. The result is that the olive oil is marketed at a quite contained price, which attracts consumers to purchase it.

In this global context, Italian producers of extra-virgin olive oil, often consisting of small local family businesses, struggle to be competitive, whilst keeping high their products quality. In this context, despite the global competition, three issues were found by D'Adamo et al. [35] to be crucial for revitalising the sector and making it more competitive: (i) the attention of consumers towards the natural resources, (ii) the sense of family associated with olive oil's life cycle and (iii) the strategic role played by family business OOMs giving a great sense of trust.

Finally, the SWOT analysis documented that the application of CE principles enables the conversion of the solid/liquid waste associated with the olive oil supply chain into zeroburden resources. The latter are then utilised for production of value-added energy and bio-based materials, giving the opportunity to the OOM owners to have additional income, though the feasibility of recovery plants is highly affected by economies of scale [35].

\section{Conclusions}

The SI attained the aim of collecting selected relevant studies to address sustainability issues associated with resource recovery from waste management in the CE. Under this perspective, to the guest editors' opinions, the SI further contributed to the awareness that waste can be sustainably converted as zero-burden resources into valued-added material and energy commodities.

Furthermore, the SI allowed the understanding that CE principles can be applied to a wide range of sectors and topics, and that there are several scientifically based methodologies, including LCA, that can be used for assessing and improving the sustainability of CE solutions in an integrated, holistic approach.

Those methodologies were confirmed by this SI's articles to be quite effective in scientifically assessing the effects that $\mathrm{CE}$ measures can have upon the systems which they are applied to.

None of the reviewed papers applied LCSA, thereby confirming what was stated in the introductory section of this editorial. In this regard, the guest editors wish that this editorial's findings will stimulate application of LCSA for the integrated overview of the three dimensions of sustainability in the waste management field. 
All articles included in this SI were characterised by a clear discussion of the key features and contributions of the studies, which were carried out with a focus on practical applications beyond theoretical discussions. This made those articles even more effective in advancing the knowledge on the subject, and confirmed that- to be reliable-any CE assessment should start with the modelling of existing systems using specific data, so that then it can be generalised, projected to the future and used as the starting point to develop long-term best practices.

Spierling et al. [30] highlighted the importance of assessing the environmental profile of different end-of-life options of bio-based plastics from the early design on, to contribute to enabling sound $\mathrm{CE}$ models in such a widely used group of plastics. Tua et al. [11] contributed to understanding that packaging reuse is, overall, an environmentally and economically effective practice to maintain the value of products as long as possible, in compliance with CE principles. Ochoa et al. [31] offered a systematic approach for multi-objective optimisation of different ORC configurations using thermal, economic and environmental criteria. Moreschi et al. [32] contributed to the currently available specialised literature by defining a DSS that allows for the setting up of waste management strategies under emergency conditions relying only upon third parties' waste disposal plants. Gallo et al. [33] used their study to put emphasis upon the need for development of methodologies that are specific for the environmental assessment of ship waste management systems. Ho et al. [34] provided important information to support material efficiency as a key strategy for CE promotion and, though being limited to the Malaysian context, could be used as guidelines for similar types of study and be extended to other demographic configurations. D'Adamo et al. [35] enabled understanding that family owned OOMs have a greatly positive effect on trust and purchase intention of consumers. In the light of this, there would be the need to further investigate the effect of CE principles to create valuable synergies amongst OOMs, making it possible for the Italian high-quality olive oil compartment to regain global competitiveness in sustainable manners.

Finally, the response to this SI can be considered to be particularly encouraging, as it proves once again that academic communities keep on doing research on the relevant aspects associated with the beneficial interaction between $\mathrm{CE}$ and sustainability in a wide range of sectors, so making this SI a valid platform for knowledge advancement.

Author Contributions: Writing—original draft preparation, C.I.; writing—review and editing, C.I., C.A., V.S., M.N., M.T. All authors have read and agreed to the published version of the manuscript.

Funding: This research received no external funding.

Acknowledgments: Carlo Ingrao, as the Managing Guest Editor of this SI, would like to convey his most heartfelt gratitude to his guest editors because, without their supportive commitment and work, this SI would have not come true. In addition to this, the whole guest editorial board would like to thank the authors for the high quality of the manuscripts they have contributed. The relevant work they have developed will make this SI a valid tool to spread knowledge on ways the sustainability of waste management systems can be improved through application of CE principles. Finally, special thanks are conveyed to Damien Giurco (Esteemed Editor-in-Chief), along with Sammy Wang (Assistant Editor) for having supported, guided and supervised the development of this SI project since the very beginning of its conception.

Conflicts of Interest: The authors declare no conflict of interest.

\section{References}

1. Mondello, G.; Salomone, R.; Ioppolo, G.; Saija, G.; Sparacia, S.; Lucchetti, M.C. Comparative LCA of Alternative Scenarios for Waste Treatment: The Case of Food Waste Production by the Mass-Retail Sector. Sustainability 2017, 9, 827. [CrossRef]

2. EU. EC Directive 2008/98/EC of The European Parliament and of the Council of 19 November 2008 on Waste and Repealing Certain Directives 2008. Available online: https:/ / eur-lex.europa.eu/legal-content/EN/TXT/?uri=celex\%3A32008L0098 (accessed on 7 March 2021).

3. Goulart Coelho, L.M.; Lange, L.C. Applying life cycle assessment to support environmentally sustainable waste management strategies in Brazil. Resour. Conserv. Recycl. 2018, 128, 438-450. [CrossRef] 
4. Govindan, K. Green sourcing: Taking steps to achieve sustainability management and conservation of resources. Resour. Conserv. Recycl. 2015, 104, 329-333. [CrossRef]

5. Zaman, A.U.; Swapan, M.S.H. Performance evaluation and benchmarking of global waste management systems. Resour. Conserv. Recycl. 2016, 114, 32-41. [CrossRef]

6. Põldnurk, J. Optimisation of the economic, environmental and administrative efficiency of the municipal waste management model in rural areas. Resour. Conserv. Recycl. 2015, 97, 55-65. [CrossRef]

7. Ingrao, C.; Arcidiacono, C.; Bezama, A.; Ioppolo, G.; Winans, K.; Koutinas, A.; Gallego-Schmid, A. 2017. Sustainability issues of by-product and waste management systems, to produce building material commodities: A comprehensive review of findings from a virtual special issue. Resour. Conserv. Recycl. 2019, 146, 358-365. [CrossRef]

8. EU. Circular Economy Action Plan-For a Cleaner and More Competitive Europe. 2020. Available online: https:/ / ec.europa.eu/ environment/circular-economy/pdf/new_circular_economy_action_plan.pdf (accessed on 16 March 2021).

9. Fogarassy, C.; Finger, D. Theoretical and practical approaches of circular economy for business models and technological solutions. Resources 2020, 9, 76. [CrossRef]

10. Ingrao, C.; Faccilongo, N.; Di Gioia, L.; Messineo, A. Food waste recovery into energy in a circular economy perspective: A comprehensive review of aspects related to plant operation and environmental assessment. J. Clean. Prod. 2018, 184, 869-892. [CrossRef]

11. Tua, C.; Biganzoli, L.; Grosso, M.; Rigamonti, L. Life cycle assessment of reusable plastic crates (RPCs). Resources 2019, 8, 110. [CrossRef]

12. Corona, B.; Shen, L.; Reike, D.; Rosales Carreón, J.; Worrell, E. Towards sustainable development through the circular economy-A review and critical assessment on current circularity metrics. Resour. Conserv. Recycl. 2019, 151, 104498. [CrossRef]

13. Geissdoerfer, M.; Savaget, P.; Bocken, N.M.; Hultink, E.J. The Circular Economy-A new sustainability paradigm? J. Clean. Prod. 2017, 143, 757-768. [CrossRef]

14. Hysa, E.; Kruja, A.; Rehman, N.U.; Laurenti, R. Circular economy innovation and environmental sustainability impact on economic growth: An integrated model for sustainable development. Sustainability 2020, 12, 4831. [CrossRef]

15. Kirchherr, J.; Reike, D.; Hekkert, M. Conceptualizing the circular economy: An analysis of 114 definitions. Resour. Conserv. Recycl. 2017, 127, 221-232. [CrossRef]

16. Aznar-Sánchez, J.A.; Mendoza, J.M.F.; Ingrao, C.; Failla, S.; Bezama, A.; Nemecek, T.; Gallego-Schmid, A. Indicators for Circular Economy in the Agri-food Sector. Resour. Conserv. Recycl. 2019, 163, 105028.

17. Valenti, F.; Porto, S.M.C.; Chinnici, G.; Selvaggi, R.; Cascone, G.; Arcidiacono, C.; Pecorino, B. Use of citrus pulp for biogas production: A GIS analysis of citrus growing areas and processing industries in South Italy. Land Use Policy 2017, 66, 151-161. [CrossRef]

18. Sehnem, S.; Vazquez-Brust, D.; Pereira, S.C.F.; Campos, L.M.S. Circular economy: Benefits, impacts and overlapping. Supply Chain Manag. 2019, 24, 784-804. [CrossRef]

19. EEA. Cutting Greenhouse Gas Emissions through Circular Economy Actions in the Buildings Sector; Briefing No. 06/2020. Available online: https: / / www.eea.europa.eu/downloads/3cf188c4dab74be7adca0381c303d8e6/1606129107/cutting-greenhousegas-emissions-through.pdf (accessed on 30 March 2021).

20. Finkbeiner, M.; Schau, E.M.; Lehmann, A.; Traverso, M. Towards life cycle sustainability assessment. Sustainability 2010, 2, 3309-3322. [CrossRef]

21. Traverso, M.; Finkbeiner, M.; Jørgensen, A.; Schneider, L. Life cycle sustainability dashboard. J. Ind. Ecol. 2012, 16, 680-688. [CrossRef]

22. Finkbeiner, M. Nachhaltigkeitsbewertung von Produkten und Prozessen-Vom Leitbild zur Umsetzung. In Proceedings of the 12. Produktionstechnisches. Kolloquium PTK, 11, Berlin, Germany, 10 December 2007.

23. Klöpffer, W. Life cycle sustainability assessment of products. Int. J. Life Cycle Assess. 2008, 13, 89-95. [CrossRef]

24. Laurent, A.; Bakas, I.; Clavreul, J.; Bernstad, A.; Niero, M.; Gentil, E.; Hauschild, M.Z.; Christensen, T.H. Review of LCA studies of solid waste management systems-Part I lessons learned and perspectives. Waste Manag. 2014, 34, 573-588. [CrossRef]

25. Laurent, A.; Clavreul, J.; Bernstad, A.; Bakas, I.; Niero, M.; Gentil, E.; Christensen, T.H.; Hauschild, M.Z. Review of LCA studies of solid waste management systems-Part II: Methodological guidance for a better practice. Waste Manag. 2014, 34, 589-606. [CrossRef] [PubMed]

26. Rigamonti, L.; Niero, M.; Haupt, M.; Grosso, M.; Judl, J. Recycling processes and quality of secondary materials: Food for thought for waste-management-oriented life cycle assessment studies. Waste Manag. 2018, 76, 261-265. [CrossRef] [PubMed]

27. Rigamonti, L.; Taelman, S.E.; Huysveld, S.; Sfez, S.; Ragaert, K.; Dewulf, J. A step forward in quantifying the substitutability of secondary materials in waste management life cycle assessment studies. Waste Manag. 2020, 114, 331-340. [CrossRef] [PubMed]

28. Ingrao, C.; Bacenetti, J.; Bezama, A.; Blok, V.; Goglio, P.; Koukios, E.G.; Lindner, M.; Nemecek, T.; Siracusa, V.; Zabaniotou, A.; et al. The potential roles of bio-economy in the transition to equitable, sustainable, post fossil-carbon Societies: Findings from this virtual special issue. J. Clean. Prod. 2018, 204, 471-488. [CrossRef]

29. Cecchin, A.; Salomone, R.; Deutz, P.; Raggi, A.; Cutaia, L. What Is in a Name? The Rising Star of the Circular Economy as a Resource-Related Concept for Sustainable Development. Circ. Econ. Sustain. 2021. [CrossRef] 
30. Spierling, S.; Venkatachalam, V.; Mudersbach, M.; Becker, N.; Herrmann, C.; Endres, H.-J. End-of-Life Options for Bio-Based Plastics in a Circular Economy-Status Quo and Potential from a Life Cycle Assessment Perspective. Resources 2020, 9, 90. [CrossRef]

31. Ochoa, G.V.; Gutierrez, J.C.; Forero, J.D. Exergy, Economic, and Life-Cycle Assessment of ORC System for Waste Heat Recovery in a Natural Gas Internal Combustion Engine. Resources 2020, 9, 2. [CrossRef]

32. Moreschi, L.; Del Borghi, A.; Taramasso, A.C.; Gallo, M. Waste management under emergency conditions: Life-cycle multicriteria analysis as decision support system. Resources 2020, 9, 82. [CrossRef]

33. Gallo, M.; Moreschi, L.; Mazzoccoli, M.; Marotta, V.; Del Borghi, A. Sustainability in maritime sector: Waste management alternatives evaluated in a circular carbon economy perspective. Resources 2020, 9, 41. [CrossRef]

34. Ho, F.H.; Abdul-Rashid, S.H.; Ghazilla, R.A.R.; Woo, Y.L. Resources sustainability through material efficiency strategies: An insight study of electrical and electronic companies. Resources 2019, 8, 117. [CrossRef]

35. D'Adamo, I.; Falcone, P.M.; Gastaldi, M.; Morone, P. A Social Analysis of the Olive Oil Sector: The Role of Family Business. Resources 2019, 8, 151. [CrossRef]

36. Ingrao, C.; Evola, R.S.; Cantore, P.; De Bernardi, P.; Del Borghi, A.; Vesce, E.; Beltramo, R. The contribution of sensor-based equipment to life cycle assessment through improvement of data collection in the industry. Environ. Impact Assess. Rev. 2021, 88, 106569. [CrossRef]

37. Stahel, W.R. The Circular Economy. Nature 2016, 531, 436-438. [CrossRef] [PubMed] 